\title{
Spironolactone alleviates late cardiac remodeling after left ventricular restoration surgery
}

\author{
Masaki Tsukashita, MD, ${ }^{a}$ Akira Marui, MD, PhD, ${ }^{a}$ Takeshi Nishina, MD, PhD, ${ }^{a}$ Eiji Yoshikawa, MD, ${ }^{a}$

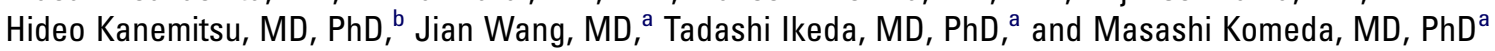

Objective: Although left ventricular restoration is effective for treating ischemic cardiomyopathy caused by left ventricular remodeling and redilation, the initial improvement in left ventricular function is not always sustained. We have reported that the inhibition of the renin-angiotensin-aldosterone system by angiotensin-converting enzyme inhibitors and angiotensin receptor blockers is effective in preventing late remodeling after left ventricular restoration. However, the effects of spironolactone-an aldosterone blocker-after left ventricular restoration have not been elucidated.

Methods: Myocardial infarction was induced by ligating the left anterior descending artery. The rats developed left ventricular aneurysms and underwent left ventricular restoration by the plication of the left ventricular aneurysm 4 weeks after the ligation. Thereafter, the rats were randomized into a left ventricular restoration (vehicle) group and left ventricular restoration with spironolactone $(100 \mathrm{mg} / \mathrm{kg} / \mathrm{d}$, by mouth) group.

Results: Echocardiography revealed that in the left ventricular restoration with spironolactone group, late cardiac redilation was significantly attenuated (left ventricular end-diastolic area: $0.51 \pm 0.03 \mathrm{~cm}^{2}$ vs $\left.0.63 \pm 0.03 \mathrm{~cm}^{2}, P<.05\right)$ and late left ventricular function was preserved (fractional area change: $48.8 \% \pm 3.0 \%$ vs $35.8 \% \pm$ $2.4 \%, P<.01)$. Hemodynamically, rats in the left ventricular restoration with spironolactone group exhibited improved systolic function (maximal end-systolic pressure-volume relationship: $0.38 \pm 0.03 \mathrm{~mm} \mathrm{Hg} / \mu \mathrm{L}$ vs $0.11 \pm 0.04 \mathrm{~mm} \mathrm{Hg} / \mu \mathrm{L}, P<$ $.01)$ and diastolic function $(\tau: 18.5 \pm 1.5 \mathrm{sec}$ vs $23.1 \pm 1.4 \mathrm{sec}, P<.05)$ than those in the LVR group. Histologically, interstitial fibrosis in the remote area was significantly reduced $(5.6 \% \pm 1.3 \%$ vs $12 \% \pm 1.0 \%, P<.01)$, and fibrosis around the pledgets (near area) was also attenuated in the left ventricular restoration with spironolactone group. The myocardial messenger ribonucleic acid expressions of transforming growth factor- $\beta 1$ and brain natriuretic peptide measured using the real-time polymerase chain reaction were lower in the left ventricular restoration with spironolactone group (transforming growth factor- $\beta 1$ : $0.13 \pm 0.02$ vs $0.28 \pm$ $0.02, P<.01$; brain natriuretic peptide: $0.99 \pm 0.14$ vs $1.54 \pm 0.18, P<.05$ ).

From the Department of Cardiovascular Surgery, Kyoto University Graduate School of Medicine, ${ }^{\mathrm{a}}$ Kyoto, Japan; and Hamamatsu Rosai Hospital, ${ }^{\mathrm{b}}$ Shizuoka, Japan.

Received for publication May 16, 2007; revisions received Sept 13, 2007; accepted for publication Nov 13, 2007.

Address for reprints: Masaki Tsukashita, MD, Department of Cardiovascular Surgery, Kyoto University Graduate School of Medicine, 54 Shogoin-Kawara, Sakyo, Kyoto 606-8507, Japan (E-mail: mtsuka@kuhp. kyoto-u.ac.jp).

J Thorac Cardiovasc Surg 2008;136:58-64 $0022-5223 / \$ 34.00$

Copyright $(2008$ by The American Association for Thoracic Surgery

doi:10.1016/j.jtcvs.2007.11.016
The systemic blood pressure and heart rate did not differ between the 2 groups.

Conclusion: Spironolactone reduced the gene expression of transforming growth factor- $\beta 1$ and brain natriuretic peptide and alleviated not only cardiac redilation but also the deterioration of left ventricular function late after left ventricular restoration without inducing hypotension, a major side effect of angiotensin-converting enzyme inhibitors or angiotensin receptor blocker. Spironolactone is a promising therapeutic option for alleviating remodeling after left ventricular restoration.

$\mathrm{L}$ eft ventricular restoration (LVR) surgery after myocardial infarction (MI) is effective as a surgical treatment for left ventricular (LV) aneurysm or ischemic cardiomyopathy. ${ }^{1-5}$ However, LV redilation and functional deterioration after LVR are serious problems. ${ }^{6-8}$

The renin-angiotensin-aldosterone system (RAAS) has been reported to play an important role in LV remodeling after MI. We have demonstrated that angiotensinconverting enzyme inhibitors (ACEIs), angiotensin receptor blockers (ARBs), and 
pledgets, the LV wall was divided into 4 areas. The 2 areas adjacent to the pledgets were called the "near areas," and the other 2 areas were called the "remote areas."7 The images were viewed using an Eclipse E600 Nikon (Tokyo, Japan) microscope. The digitally acquired images were analyzed using the IPLab imaging software (Version 3.71 for Windows; Scanalytics Inc, Rockville, Md). The results of the planimetry of myocardial fibrosis were analyzed as previously described. ${ }^{10}$ The histopathologic results were analyzed in a blind manner.

\section{Quantitative Real-time Polymerase Chain Reaction}

The remaining $\mathrm{LV}$ muscles were stored at $-80^{\circ} \mathrm{C}$ until use. The extraction of messenger ribonucleic acid (mRNA) from tissue samples and polymerase chain reaction were performed as previously described. ${ }^{10}$

The nucleotide sequence for primers and TaqMan probes were as follows: brain natriuretic peptide (BNP), forward primer: $5^{\prime}$-GATC CAGGAGAGACTTCGAAA-3'; reverse primer: 5'-CGGTTATC TTCTGCCCAA- $3^{\prime}$; TaqMan probe: $5^{\prime}$-TCCAAGATGGCACATA GTTCAAGCTG- $3^{\prime}$; transforming growth factor (TGF)- $\beta 1$, forward primer: 5'-GGCAGTGGCGAACCAAG-3'; reverse primer: $5^{\prime}$-CT GTCACAAGAGCAGTGAGCA-3'; TaqMan probe: 5'-AGACG GAATACAGGGCTTTCGCTTC- $3^{\prime}$. The TaqMan rodent glyceraldehyde-3-phosphate dehydrogenase (GAPDH) control reagents were used to detect rat GAPDH as the internal standard. The expression levels of the target genes were normalized to the GAPDH level in each sample.

\section{Statistical Analysis}

All data are presented as means \pm standard deviation. To analyze echocardiographic data, multiple group comparisons were performed using 1-way analysis of variance. In multiple comparisons among independent groups in which analysis of variance indicated significant differences, the statistical value was determined according to the Bonferroni/Dunn post hoc test. All data comparing LVR group and LVR-Sp group were analyzed with the Wilcoxon ranksum test. Statistical analyses were performed with StatView for Windows (version 5.0; SAS Institute Inc, Cary, NC).

\section{Results}

All of the rats survived LVR surgery. There was no difference in systolic blood pressure levels between the 2 groups at 4 weeks after $\operatorname{LVR}(109.5 \pm 5.8 \mathrm{~mm} \mathrm{Hg}$ vs $111.3 \pm 8.6$ $\mathrm{mm} \mathrm{Hg}$ ). The heart rate was higher in the LVR-Sp group than in the LVR group $(367 \pm 39$ beats/min vs $400 \pm 38$ beats/min, respectively). However, this difference was not statistically significant.

\section{Echocardiography}

The 2-dimensional echocardiography data before LVR and 1 day and 4 weeks after LVR are summarized in Table 1. Before LVR and 1 day after LVR, no differences were observed between the echocardiographic data of the 2 groups. The akinetic area was $35 \% \pm 6 \%$ in the LVR group and $33 \% \pm 4 \%$ in the LVR-Sp group. One day after LVR, the left ventricular enddiastolic area (LVEDA) decreased compared with the preoperative values in both groups (from $0.92 \pm 0.02 \mathrm{~cm}^{2}$ to $0.32 \pm$
$0.04 \mathrm{~cm}^{2}$ in the LVR-Sp group $[P<.05]$ and from $0.91 \pm$ $0.03 \mathrm{~cm}^{2}$ to $0.34 \pm 0.03 \mathrm{~cm}^{2}$ in the LVR group $\left.[P<.05]\right)$. The left ventricular end-systolic area (LVESA) also decreased in both groups (from $0.70 \pm 0.02 \mathrm{~cm}^{2}$ to $0.11 \pm 0.04 \mathrm{~cm}^{2}$ in the LVR-Sp group $[P<.05]$ and from $0.66 \pm 0.03 \mathrm{~cm}^{2}$ to $0.12 \pm 0.05 \mathrm{~cm}^{2}$ in the LVR group $\left.[P<.05]\right)$

Four weeks after LVR, the LVEDA and LVESA values demonstrated an increase in comparison with the values recorded immediately after surgery in the LVR group (LVEDA: from $0.34 \pm 0.03$ to $0.63 \pm 0.03 \mathrm{~cm}^{2}[P<.05]$ and LVESA: from $0.12 \pm 0.05$ to $0.40 \pm 0.08 \mathrm{~cm}^{2}[P<$ .05]). Although the LVEDA and LVESA values also increased in the LVR-Sp group, the LVEDA value was lower in the LVR-Sp group than in the LVR group at 4 weeks after $\operatorname{LVR}\left(0.51 \pm 0.03 \mathrm{~cm}^{2}\right.$ vs $\left.0.63 \pm 0.03 \mathrm{~cm}^{2}, P<.05\right)$

Immediately after LVR, the fractional area change (FAC) demonstrated an increase (from $24.2 \% \pm 1.0 \%$ to $65.7 \% \pm$ $3.1 \%$ in the LVR-Sp group $[P<.05]$ and from $26.6 \% \pm$ $1.6 \%$ to $66.5 \% \pm 2.6 \%$ in the LVR group $[P<.05])$. The time course of the FAC is shown in Figure 1. The FAC decreased gradually after LVR in both groups. However, the FAC at 4 weeks after LVR was significantly higher in the LVR-Sp group than in the LVR group $(48.8 \% \pm 3.0 \%$ vs $35.8 \% \pm 2.4 \%$, respectively; $P<.01$ ).

\section{Hemodynamic Evaluation}

The results of cardiac catheterization 4 weeks after LVR are summarized in Table 2. The LV end-diastolic pressure values did not differ between the 2 groups $(12.7 \pm 5.9 \mathrm{~mm} \mathrm{Hg}$ vs $13.4 \pm 8.1 \mathrm{~mm} \mathrm{Hg}$ ). In the LVR-Sp group, however, the Emax, $+\mathrm{LV} \mathrm{dP} / \mathrm{dt}$, and $-\mathrm{LV} \mathrm{dP} / \mathrm{dt}$ values were higher than those in the LVR group; the $\tau$ value was lower than that in the LVR group (Emax: $0.38 \pm 0.03 \mathrm{~mm} \mathrm{Hg} / \mu \mathrm{L}$ vs $0.11 \pm$ $0.04 \mathrm{~mm} \mathrm{Hg} / \mu \mathrm{L}, P<.01 ;+\mathrm{LV} \mathrm{dP} / \mathrm{dt}: 6568.7 \pm 1096.3$ $\mathrm{mm} \mathrm{Hg} / \mathrm{sec}$ vs $5212.4 \pm 590.1 \mathrm{~mm} \mathrm{Hg} / \mathrm{sec}, P<.01 ;-\mathrm{LV}$ $\mathrm{dP} / \mathrm{dt}: 4011.9 \pm 554.6 \mathrm{~mm} \mathrm{Hg} / \mathrm{sec}$ vs $3368.9 \pm 706.2 \mathrm{~mm}$ $\mathrm{Hg} / \mathrm{sec}, P<.05$; and $\tau: 18.5 \pm 1.5 \mathrm{sec}$ vs $23.1 \pm 1.4 \mathrm{sec}$, $P<.05 ;$ LVR-Sp vs LVR, respectively).

\section{Heart and Lung Weight}

Four weeks after LVR, the body weight (BW) of the rats in the LVR-Sp group (407.2 $\pm 52.8 \mathrm{~g}$ ) was similar to that of the rats in the LVR group $(390.3 \pm 44.3 \mathrm{~g})$. The left ventricular weight (LVW) and lung weight normalized to BW were lower in the LVR-Sp group compared with the LVR group (LVW/ BW: $2.14 \pm 0.1 \mathrm{~g} / \mathrm{kg}$ vs $2.96 \pm 1.2 \mathrm{~g} / \mathrm{kg}, P<.05 ;$ lung weight/BW: $8.6 \pm 3.1 \mathrm{~g} / \mathrm{kg}$ vs $10.9 \pm 1.7 \mathrm{~g} / \mathrm{kg}$, respectively, $P<.05$ ) (Figure 2). Right ventricular weight/BW did not differ between the 2 groups $(1.1 \pm 0.3$ for LVR-Sp vs $1.3 \pm 0.3$ for LVR).

\section{Histopathology}

Representative photographs of histopathologic findings are shown in Figures 3 and 4. The interstitial fibrosis in the remote 
TABLE 1. Echocardiographic data

\begin{tabular}{|c|c|c|c|c|c|c|c|c|}
\hline & \multirow[b]{2}{*}{ Normal } & \multirow[b]{2}{*}{ MI } & \multicolumn{2}{|c|}{ Pre-LVR } & \multicolumn{2}{|c|}{$1 \mathrm{~d}$ after LVR } & \multicolumn{2}{|c|}{4 wk after LVR } \\
\hline & & & LVR & LVR-Sp & LVR & LVR-Sp & LVR & LVR-Sp \\
\hline $\operatorname{LVEDD}(\mathrm{cm})$ & $0.86 \pm 0.03$ & $1.12 \pm 0.06$ & $1.08 \pm 0.05$ & $1.06 \pm 0.06$ & $0.64 \pm 0.02 \ddagger$ & $0.64 \pm 0.03 \ddagger$ & $0.95 \pm 0.02$ & $0.83 \pm 0.02^{*}$ \\
\hline LVESD(cm) & $0.52 \pm 0.05$ & $0.96 \pm 0.04$ & $0.91 \pm 0.05$ & $0.90 \pm 0.05$ & $0.35 \pm 0.08 \ddagger$ & $0.35 \pm 0.11 \ddagger$ & $0.79 \pm 0.06$ & $0.68 \pm 0.06 \dagger$ \\
\hline $\operatorname{LVEDA}\left(\mathrm{cm}^{2}\right)$ & $0.57 \pm 0.07$ & $0.96 \pm 0.1$ & $0.91 \pm 0.03$ & $0.92 \pm 0.02$ & $0.34 \pm 0.03 \ddagger$ & $0.32 \pm 0.04$ & $0.63 \pm 0.03$ & $0.51 \pm 0.03^{*}$ \\
\hline $\operatorname{LVESA}\left(\mathrm{cm}^{2}\right)$ & $0.21 \pm 0.06$ & $0.72 \pm 0.07$ & $0.66 \pm 0.07$ & $0.70 \pm 0.08$ & $0.12 \pm 0.05 \ddagger$ & $0.11 \pm 0.04 \ddagger$ & $0.40 \pm 0.08$ & $0.35 \pm 0.10$ \\
\hline $\mathrm{FAC}(\%)$ & $63.6 \pm 1.7$ & $24.9 \pm 1.5$ & $26.6 \pm 1.6$ & $24.2 \pm 1.0$ & $66.5 \pm 2.6 \ddagger$ & $65.7 \pm 3.1 \ddagger$ & $35.8 \pm 2.4$ & $48.8 \pm 3.0 \dagger$ \\
\hline
\end{tabular}

$\angle V R$, Left ventricular restoration; $L V E D D$, left ventricular end-diastolic diameter; $L V E S D$, left ventricular end-systolic diameter; $L V E D A$, left ventricular end-diastolic area; $L V E S A$, left ventricular end-systolic area; $F A C$, fractional area change. ${ }^{*} P<.05 . \dagger P<.01$ versus $\operatorname{LVR}$. $\ddagger P<.05$ versus pre-LVR state.

area was attenuated in the LVR-Sp group (Figure 3). A lower percentage of myocardial fibrosis in the remote area was observed in the LVR-Sp group compared with the LVR group $(5.6 \% \pm 1.3 \%$ vs $12 \% \pm 1.0 \%$, respectively, $P<.05)$. In the LVR group, interstitial fibrosis was thick and partially composed of a reticular structure surrounding the myocardial fibers. On the other hand, the fibrosis was thin and scattered among the myocardial fibers in the LVR-Sp group. Severe fibrosis developed around the pledgets (near area) in the LVR group (Figure 4). However, the fibrosis around the pledgets was attenuated in the LVR-Sp group.

\section{Reverse Transcriptase Polymerase Chain Reaction}

The results of reverse transcriptase polymerase chain reaction are shown in Figure 5. Spironolactone inhibited the expressions of TGF- $\beta 1$ and BNP mRNA (TGF- $\beta 1 /$ GAPDH: 0.13 \pm 0.02 vs $0.28 \pm 0.02, P<.005$; BNP/GAPDH: $0.99 \pm$ 0.14 vs $1.54 \pm 0.18, P<.05 ;$ LVR-Sp vs LVR, respectively).

\section{Discussion}

\section{Major Findings}

By using hemodynamic, histologic, and molecular methods, we showed that spironolactone attenuated car-

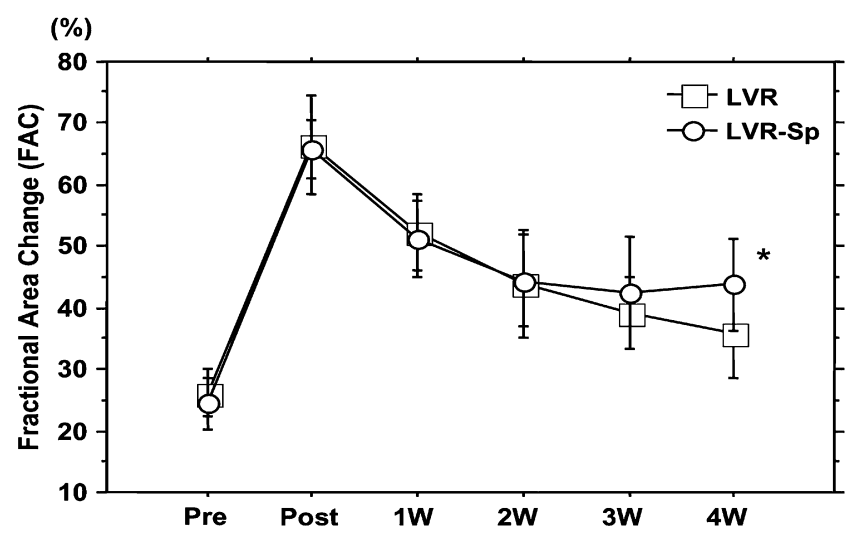

Figure 1. The time course of FAC calculated from the echocardiographic data obtained from LVR (closed circles) and LVR-Sp (closed squares) groups. ${ }^{*} P<.05$ versus LVR. Values are represented as mean \pm standard deviation. $L V R$, Left ventricular restoration; LVR-Sp, left ventricular restoration with spironolactone. diac remodeling and preserved systolic and diastolic function late after LVR. LVEDD and LVEDA values were lower; FAC, Emax, and $+\mathrm{LV} \mathrm{dP} / \mathrm{dt}$ values were higher; and the $\tau$ value was lower in the LVR-Sp group than in the LVR group. Lower values of LVW/BW and lung weight/BW in the LVR-Sp group indicate that spironolactone attenuated LV hypertrophy and lung congestion induced by LV dysfunction. Histopathologically, spironolactone prevented the accumulation of connective tissue in both the near and remote areas. The expressions of TGF$\beta 1$ mRNA, which is related to adverse remodeling, and BNP mRNA, which indicates LV wall stress, were inhibited. One of the most impressive results of this study was that spironolactone did not induce severe hypotension in the rats exposed to such a critical condition after LVR surgery.

\section{Renin-Angiotensin-Aldosterone System and Cardiac Remodeling After Left Ventricular Restoration}

LVR is an effective treatment for LV aneurysm and ischemic cardiomyopathy after MI. ${ }^{1-5}$ However, several clinical and experimental studies have reported cardiac redilation and functional deterioration late after LVR. ${ }^{6-8}$ Although the precise mechanism of LV redilation after LVR has not been fully elucidated, we and others have demonstrated that progressive fibrosis in areas both near and remote from the

TABLE 2. Results of cardiac catheterization 4 weeks after left ventricular restoration

\begin{tabular}{lcc}
\hline & LVR & LVR-Sp \\
\hline LVEDP $(\mathrm{mm} \mathrm{Hg})$ & $13.4 \pm 8.1$ & $12.7 \pm 5.9$ \\
Emax $(\mathrm{mm} \mathrm{Hg} / \mu \mathrm{L})$ & $0.11 \pm 0.04$ & $0.38 \pm 0.03 \dagger$ \\
$+\mathrm{LV} \mathrm{dP} / \mathrm{dt}(\mathrm{mm} \mathrm{Hg} / \mathrm{sec})$ & $5212.4 \pm 590.1$ & $6568.7 \pm 1096.3 \dagger$ \\
$-\mathrm{LV} \mathrm{dP} / \mathrm{dt}(\mathrm{mm} \mathrm{Hg} / \mathrm{sec})$ & $3368.9 \pm 706.2$ & $4011.9 \pm 554.6^{*}$ \\
$\tau(\mathrm{sec})$ & $23.1 \pm 1.4$ & $18.5 \pm 1.5^{*}$ \\
\hline
\end{tabular}

$L V R$, Left ventricular restoration; $L V R-S p$, Left ventricular restoration with spironolactone; $L V E D P$, left ventricular end-diastolic pressure; $+L V d P / d t$, maximal rate of left ventricular pressure development; $-L V d P / d t$, maximal rate of LV pressure relaxation; Emax, maximal end-systolic pressure-volume relationship. ${ }^{*} P<.05 . \dagger P<.01$ versus LVR. Values are mean \pm standard deviation. 

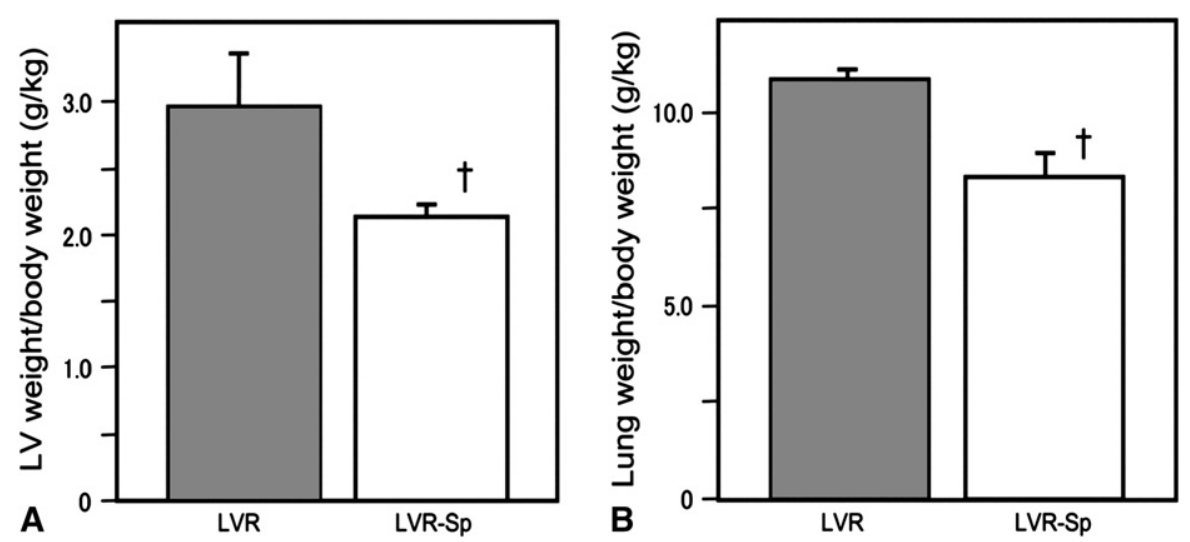

Figure 2. LV weight (A) and lung weight (B) normalized to the BW (gray bar. LVR group, white bar. LVR-Sp group). $\dagger P<$ .05 versus LVR. Values are represented as mean \pm standard deviation. $L V$, left ventricular; $L V R$, left ventricular restoration; $L V R-S p$, left ventricular restoration with spironolactone.

plicated region is one of the key factors responsible and that the RAAS plays an important role in an autocrine/paracrine manner. ${ }^{19}$ Therefore, the inhibition of the RAAS may be important in preventing persistent remodeling after the exclusion of the aneurysm by LVR and in reducing postoperative morbidity and mortality.

\section{Spironolactone}

A number of clinical and experimental studies have demonstrated the efficacy of spironolactone in the treatment of heart failure. ${ }^{16,20-23}$ Nonetheless, other RAAS inhibitors, such as ACEI and/or ARB (rather than spironolactone), are chosen in the clinical setting for the treatment of patients with chronic heart failure because these drugs are effective against hypertension, which induces cardiac hypertrophy and plays an important role in the vicious cycle of heart failure. However, these antihypertensive drugs may not be as well tolerated in acute and unstable settings after LVR surgery as they are in chronic heart failure.

One of the rationales behind the choice of spironolactone as a treatment option after LVR was that it does not act as a vasodilator and rarely induces hypotension. ${ }^{13}$ In this study, treatment with spironolactone for 4 weeks did not induce hypotension. Although the higher heart rate observed in the rats treated with spironolactone could be caused by the differences in the LV output, these differences were not statistically significant.

Further, recent studies have indicated that the onceinhibited production of aldosterone often increases and that the anti-remodeling effects of ACEI and ARB therapy decrease during their long-term administration (aldosterone escape phenomenon). ${ }^{24}$ Although the precise mechanism of this phenomenon has not been well elucidated, the induction of angiotensin-converting enzyme, the conversion of angiotensin II from angiotensin I through enzymatic pathways other than angiotensin-converting enzyme (eg, chymase), or both may play important roles. Therefore, some investigators have suggested that ACEI or ARB treatment is not adequate, and a combination of ACEI and ARB with an agent that inhibits aldosterone could be effective in preventing remodeling. ${ }^{25}$ The important point in this study is that spironolactone inhibited the expression of the gene that was related to adverse remodeling and the severity
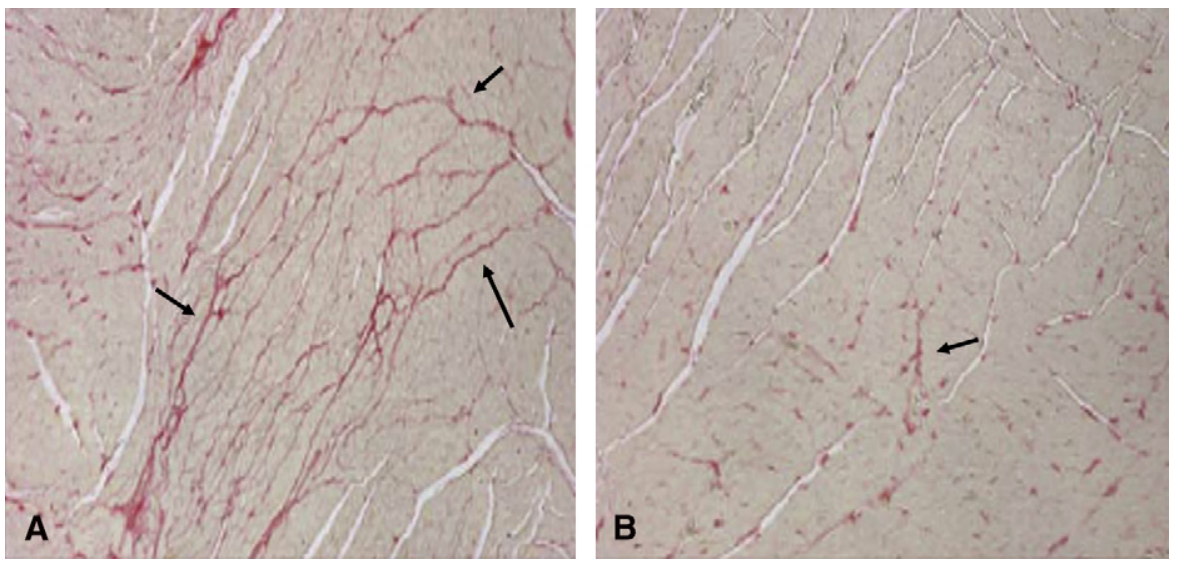

Figure 3. Histologic findings. Highpower photomicrographs $(\times 200)$ of Picrosirius red-stained $L V$ cross-section obtained from LVR (A) and LVR-Sp (B) rats. In the LVR group, the interstitial fibrosis (arrows) partially forms a reticular structure surrounding the myocardial fibers. In the LVR-Sp group, the fibrosis is thin and scatters among the myocardial fibers. 

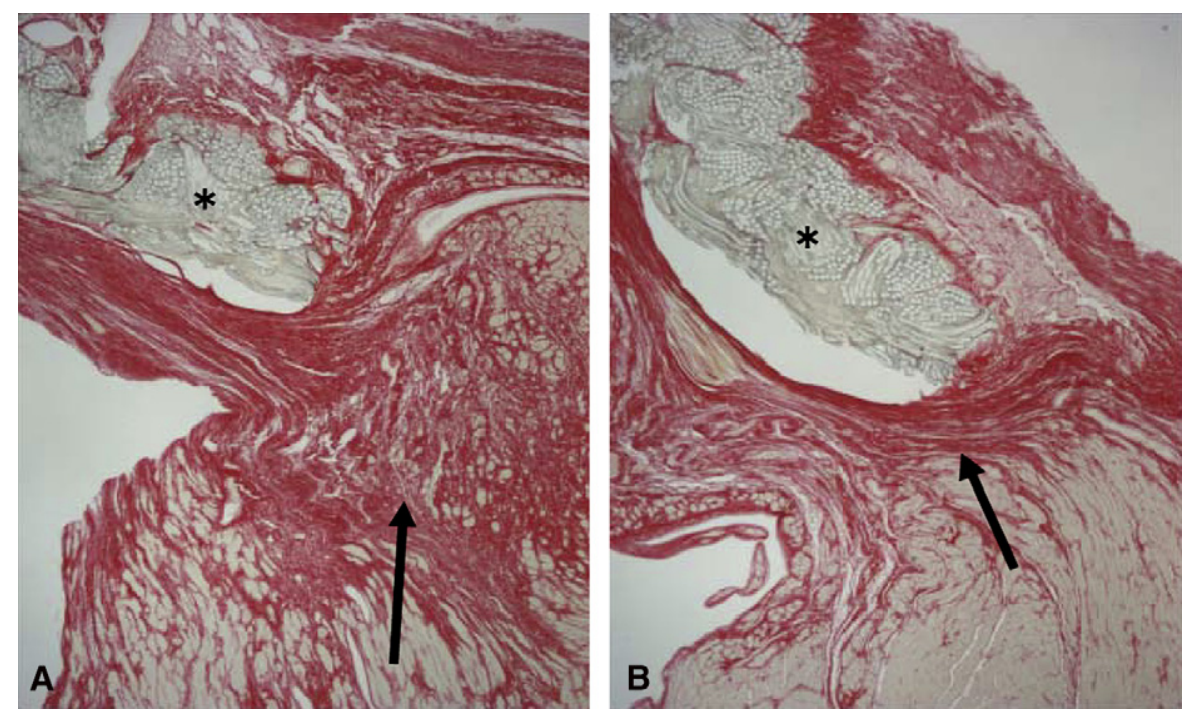

Figure 4. Low-power photomicrographs $(\times 40)$ of Picrosirius red-stained LV cross-section obtained from LVR (A) and LVR-Sp (B) groups. Dense collagen fiber (arrows) develops around the pledgets (asterisks) in the LVR group. Spironolactone attenuated fibrous accumulation.

of heart failure (TGF- $\beta 1$ and BNP). Moreover, spironolactone inhibited connective tissue aggregation both in the near and remote areas, and further attenuated LV redilation and preserved LV function without inducing hypotension.

\section{Clinical Implications}

As shown in this study, spironolactone may be well tolerated in critical and unstable settings immediately after surgery. In addition, spironolactone can be administered intravenously in patients who are unable to take drugs orally. We recommend the following with respect to spironolactone therapy. Spironolactone is the first choice immediately after LVR because these patients are often in low cardiac output states and hypotension. ACEIs and/or ARBs should be administered and titrated after patients recover from such severe conditions and are able to take drugs orally. The proper drug dose and timing of administration of each drug should be considered individually.

\section{Study Limitations}

There were several study limitations in the present study. First, the LVR method used in this study is similar to that of linear closure but not identical. In the clinical setting, the endoventricular circular patch plasty technique (first described by Dor and colleagues) is more widely performed than the linear closure methods. However, the aneurysm was completely excluded by plication, and we think that this method adequately simulated clinical LVR because the LV size decreased and LV function improved.

Second, we used the dose of $100 \mathrm{mg} / \mathrm{kg} / \mathrm{d}$ according to the previous studies that used spironolactone for an animal MI model. However, in the surgical settings used in the present study, the plasma renin level might be higher than that in the MI model. Therefore, if we had used a larger amount of spironolactone, LV redilatation would have been alleviated more.

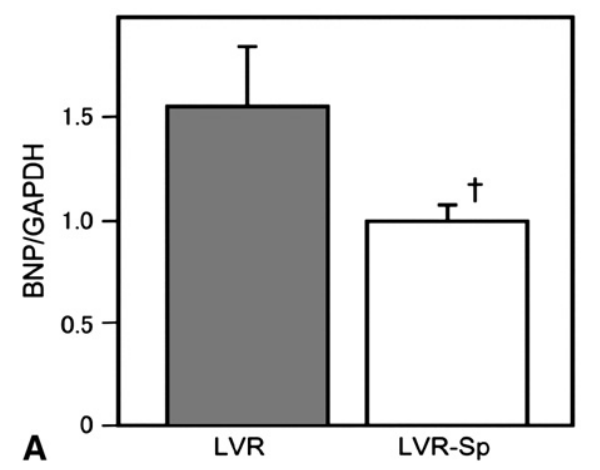$$
\text { 공 }
$$

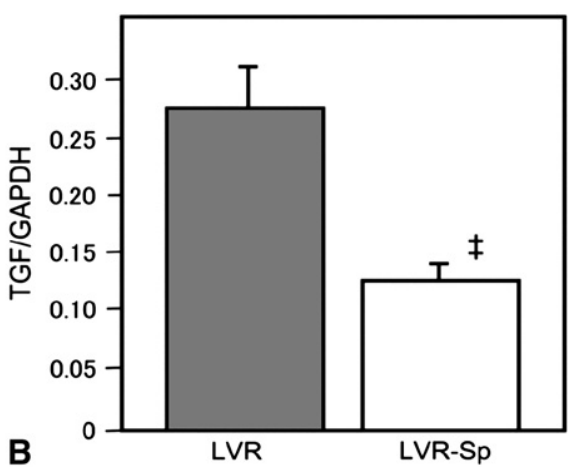

Figure 5. Myocardial expression of BNP mRNA (A) and TGF- $\beta 1$ mRNA (B) in the LVR and LVR-Sp groups 4 weeks after LVR. Data are normalized to the GAPDH expression. $\dagger \boldsymbol{P}<.05$ vs LVR. $\ddagger P<.01$ versus LVR. Values are represented as mean \pm standard deviation. $B N P$, Brain natriuretic peptide; GAPDH, glyceraldehyde-3-phosphate dehydrogenase; TGF, transforming growth factor; LVR, left ventricular restoration; $L V R-S p$, left ventricular restoration with spironolactone. 


\section{Conclusions}

Spironolactone (an aldosterone blocker) attenuated the expression of mRNA responsible for cardiac fibrosis, LV remodeling, and the deterioration in LV function after LVR without hypotension. Spironolactone is a possible therapeutic option after LVR.

\section{References}

1. Komeda M, David TE, Malik A, Ivanov J, Sun Z. Operative risks and long-term results of operation for left ventricular aneurysm. Ann Thorac Surg. 1992;53:22-9.

2. Mickleborough LL, Maruyama H, Liu P, Mohamed S. Results of left ventricular aneurysmectomy with a tailored scar excision and primary closure technique. J Thorac Cardiovasc Surg. 1994;107:690-8.

3. Kesler KA, Fiore AC, Naunheim KS, Sharp TG, Mahomed Y, Zollinger TW, et al. Anterior wall left ventricular aneurysm repair. A comparison of linear versus circular closure. J Thorac Cardiovasc Surg. 1992;103:841-8.

4. Di Donato M, Barletta G, Maioli M, Fantini F, Coste P, Sabatier M, et al. Early hemodynamic results of left ventricular reconstructive surgery for anterior wall left ventricular aneurysm. Am J Cardiol. 1992;69:886-90.

5. Dor V, Saab M, Coste P, Kornaszewska M, Montiglio F. Left ventricular aneurysm: a new surgical approach. Thorac Cardiovasc Surg. 1989;37: 11-9.

6. Dor V, Sabatier M, Di Donato M, Montiglio F, Toso A, Maioli M. Efficacy of endoventricular patch plasty in large postinfarction akinetic scar and severe left ventricular dysfunction: comparison with a series of large dyskinetic scars. J Thorac Cardiovasc Surg. 1998;116:50-9.

7. Nishina T, Nishimura K, Yuasa S, Miwa S, Nomoto T, Sakakibara Y, et al. Initial effects of the left ventricular repair by plication may not last long in a rat ischemic cardiomyopathy model. Circulation. 2001; 104:I241-5.

8. Sinatra R, Macrina F, Braccio M, Melina G, Luzi G, Ruvolo G, et al. Left ventricular aneurysmectomy; comparison between two techniques; early and late results. Eur J Cardiothorac Surg. 1997;12:291-7.

9. Nomoto T, Nishina T, Miwa S, Tsuneyoshi H, Maruyama I, Nishimura K, et al. Angiotensin-converting enzyme inhibitor helps prevent late remodeling after left ventricular aneurysm repair in rats. $\mathrm{Circu}$ lation. 2002;106:I115-9.

10. Tsuneyoshi H, Nishina T, Nomoto T, Kanemitsu H, Kawakami R, Unimonh $\mathrm{O}$, et al. Atrial natriuretic peptide helps prevent late remodeling after left ventricular aneurysm repair. Circulation. 2004;110: II174-9.

11. Nomoto T, Nishina T, Tsuneyoshi H, Miwa S, Nishimura K, Komeda M. Effects of two inhibitors of renin-angiotensin system on attenuation of postoperative remodeling after left ventricular aneurysm repair in rats. J Card Surg. 2003;18(Suppl 2):S61-8.

12. White HD, Aylward PE, Huang Z, Dalby AJ, Weaver WD, Barvik S, et al. Mortality and morbidity remain high despite captopril and/or Val- sartan therapy in elderly patients with left ventricular systolic dysfunction, heart failure, or both after acute myocardial infarction: results from the Valsartan in Acute Myocardial Infarction Trial (VALIANT). Circulation. 2005;112:3391-9.

13. Pitt B, Zannad F, Remme WJ, Cody R, Castaigne A, Perez A, et al. The effect of spironolactone on morbidity and mortality in patients with severe heart failure. Randomized Aldactone Evaluation Study Investigators. N Engl J Med. 1999;341:709-17.

14. Nishina T, Nishimura K, Yuasa S, Miwa S, Sakakibara Y, Ikeda T, et al. A rat model of ischemic cardiomyopathy for investigating left ventricular volume reduction surgery. J Card Surg. 2002;17:155-62.

15. Matsumoto R, Yoshiyama M, Omura T, Kim S, Nakamura Y, Izumi Y, et al. Effects of aldosterone receptor antagonist and angiotensin II type I receptor blocker on cardiac transcriptional factors and mRNA expression in rats with myocardial infarction. Circ J. 2004;68:376-82.

16. Silvestre JS, Heymes C, Oubenaissa A, Robert V, Aupetit-Faisant B, Carayon A, et al. Activation of cardiac aldosterone production in rat myocardial infarction: effect of angiotensin II receptor blockade and role in cardiac fibrosis. Circulation. 1999;99:2694-701.

17. Suga H, Sagawa K. Instantaneous pressure-volume relationships and their ratio in the excised, supported canine left ventricle. Circ Res. 1974;35:117-26.

18. Weiss JL, Frederiksen JW, Weisfeldt ML. Hemodynamic determinants of the time-course of fall in canine left ventricular pressure. J Clin Invest. 1976;58:751-60.

19. Pitt B, Poole-Wilson PA, Segal R, Martinez FA, Dickstein K, Camm AJ, et al. Effect of losartan compared with captopril on mortality in patients with symptomatic heart failure: randomised trial-the Losartan Heart Failure Survival Study ELITE II. Lancet. 2000;355:1582-7.

20. Mill JG, Milanez Mda C, de Resende MM, Gomes Mda G, Leite CM. Spironolactone prevents cardiac collagen proliferation after myocardial infarction in rats. Clin Exp Pharmacol Physiol. 2003;30:739-44.

21. Hayashi M, Tsutamoto T, Wada A, Tsutsui T, Ishii C, Ohno K, et al. Immediate administration of mineralocorticoid receptor antagonist spironolactone prevents post-infarct left ventricular remodeling associated with suppression of a marker of myocardial collagen synthesis in patients with first anterior acute myocardial infarction. Circulation. 2003; 107:2559-65.

22. Lal A, Veinot JP, Leenen FH. Critical role of CNS effects of aldosterone in cardiac remodeling post-myocardial infarction in rats. Cardiovasc Res. 2004;64:437-47.

23. Modena MG, Aveta P, Menozzi A, Rossi R. Aldosterone inhibition limits collagen synthesis and progressive left ventricular enlargement after anterior myocardial infarction. Am Heart J. 2001;141:41-6.

24. Jorde UP, Vittorio T, Katz SD, Colombo PC, Latif F, Le Jemtel TH. Elevated plasma aldosterone levels despite complete inhibition of the vascular angiotensin-converting enzyme in chronic heart failure. $\mathrm{Circu}$ lation. 2002;106:1055-7.

25. Katada J, Meguro T, Saito H, Ohashi A, Anzai T, Ogawa S, et al. Persistent cardiac aldosterone synthesis in angiotensin II type $1 \mathrm{~A}$ receptor-knockout mice after myocardial infarction. Circulation. 2005;111: 2157-64. 